\title{
Various Roles in the Development of EFL Learners' English Skills
}

\section{Phillip Haberman}

School of Foreign Languages, Shanghai Jiao Tong University, China, p.haberman@icloud.com

\section{Muhammad Afzaal}

PhD., Scholar, School of Foreign Languages, Shanghai Jiao Tong University, China, muhammad.afzaal1185@gmail.com

\author{
Abdul Ghaffar \\ Asst. Prof., University of Education, Multan Campus, Pakistan, \\ abdul.ghafar@ue.edu.pk
}

\section{Hind Alfadda}

Assoc. Prof., College of Education, King Saud University, Riyadh, Saudi Arabia. halfadda@ksu.edu.sa

This paper investigates the various roles found in the EFL classroom, such as native English-speaking teachers, learners' parents, and study habits outside of the classroom. During the study, the development of learners' reading comprehension, vocabulary, and writing ability was measured over the course of one semester in a weekly 2-hour English class taught by a native English speaker. Results of the change in the twenty learners' performance on reading comprehension, vocabulary, and writing ability, are drawn from pre-tests and post-tests. In both the pre and post-tests, the frequently occurring errors included articles, spelling errors, the use of fragments and run-on sentences, as well as a lack of overall coherence in the writing portion of the pre and post-tests. The study finds the learner's struggled to express their ideas properly in and academic way in both the pre and post-tests writing ability section. Based on the findings in the pre and post-tests performance of the learners, it is concluded that the role of a native English-speaking teacher in the development of learners' reading comprehension, vocabulary, and writing skills may not be as important a factor as perceived by students and parents of English language in China.

Keywords: interpersonal meaning, English as a foreign language, error analysis, native teacher, Chinese-speaking English language students

Citation: Haberman, P., Afzaal, M., Ghaffar, A., \& Alfadda, H. (2020). Various Roles in the Development of EFL Learners' English Skills. International Journal of Instruction, 13(4), 609-622. https://doi.org/10.29333/iji.2020.13438a 


\section{INTRODUCTION}

Language is a means of communication and is one of the best ways to share feelings, thoughts, emotions and ideas with others. English language is the most common foreign language around the world, so it has become the medium of communication between people from different areas around the globe. It has almost become a compulsory subject from pre-school to doctorate level. Learning a foreign language is a bit difficult as compared to teaching one's mother tongue. Many people are willing to improve their English language communication skills through different means. Every language stands upon four basic pillars including: reading, writing, listening and speaking and each person possesses different levels of English communication skills. Some of us may be good at reading and some at writing; some of us might have better speaking ability and some better listening skills; all of this depends upon a person's mentality, knowledge and confidence. Learning a foreign language has become the tool of the trade around the globe. However, it can become challenging for non-native speakers to achieve proficiency in a second language in both conversational and academic ways. According to Bazerman (1998), achieving proficiency in academic writing is necessary for university education at all graduate and post-graduate levels. He further explains that if students are unable to achieve proficiency in the writing and understating of written texts, they will be considered as incompetent in their fields. Therefore, the trend of teaching by native teachers has risen in non-native countries such as China, Arab states and Middle East. The notion has achieved a fashion in almost entire world that only native teachers can teach ESL in the best manner while ignoring the proficiency level of language even in native speakers.

In the light of above, this study focuses on the role of native teachers in ESL teaching in China. However, it is a common trend in China that native teachers are hired without linguistic ability or certification for the teaching of English language. Falvey \& Coniam (2018) argue that "the native speaker is a fine myth: we need it as a model, a goal, almost an inspiration. But it is useless as a measure". Reves \& Medgyes (1994) remarks that non-native teachers cannot the achieve the level of native teachers because of their nature and norm-dependent aptitude. Therefore, native teachers are hired and given importance in non-native countries even without their linguistic abilities and proper qualification as a language teacher than non-native professionally groomed teachers, (Arends-Kuenning \& Amin 2000; Braine 1999; Rampton, 1996). Therefore, this study focuses on the role of native teachers in ESL teaching in China. Many native teachers have been teaching English at tertiary level in China. This study is conducted in Shanghai, China and participants are non-native learners belonging to Shanghai, China. The purpose of this study to find out the effect of native teachers in teaching vocabulary, grammar and speaking ability of ESL non-native learners at tertiary level. While keeping in view, the study has following main objectives and research questions;

\section{Objectives}

1. To determine a native teacher's impact on non-native speakers' learning at tertiary level.

2. To investigate the effect of parents' roles on the development of English skills. 


\section{Research Questions}

The major research questions for the study are:

1. What impact can a native English-speaking teacher have in the EFL classroom?

2. What is the correlation between effective study habits and L2 development in the EFL classroom?

3. What effect does the parent's role play in practicing second language skills?

A lot of studies have been conducted in the area of English as a second language, and much attention has been paid to teaching process, and learners' interaction in learning a foreign language. However, less attention has been paid to the role of native teachers in ESL settings. This study focuses on the impact of native teachers and their teaching style in ESL teaching in China. Therefore, this study is significant in nature and fills in the existing gap.

\section{REVIEW OF LITERATURE}

Native teachers in ESL settings have always been encouraged. Medgyes (1992) focuses on the positive reinforcement of native teachers at tertiary level in school for teaching of English as a second language. He (1992) argues that native teacher is far better in teaching their own language in terms of strong grip on sentence structure, usage of vocabulary and more particularly in pronunciation than non-native teachers (Medgyes, 1992, p.343). While this idea is further acknowledged and supplemented by Kim (2009) as "English is spoken not only by whites, but also by many ethnic groups in several countries (p.42). Thomas (1999) also provides insights in the favour of native teachers that teachers from non-native countries such as India, Malaysia, Singapore are not as proficient as native than teachers in ESL settings in UK, the USA or other English speaking countries. Whereas, Canagarajah, Phillipson 1996, 1992 remark that "speaking more than one language provides non-native teachers awareness of language and relates their ability to students' needs". Native teachers speak in fluent way and they possess natural ability to produce sounds. In this regard, Derwing, Rossiter, Munro, and Tomson (2004) argue that "fluency, the automaticity of speech production, is a vital aspect of successful communication".

English language teaching requires a proper setting, and linguistic ability to teach effectively. The relationship of systemic function linguistic (SFL) and English teachers provides a strong awareness to analyse and observe the text material which is used in teaching material. Systemic Functional Linguistics provides an authentic gateway to analyse how meanings are developed in linguistic interactions. The textbooks which are used in non-native countries as a material for ESL teaching. Halliday (1994) projected the contribution of SFL by examining the use of linguistic interaction in terms of meaning and language use. The various facets of ideational meta-function are considered as active contestants in the depiction of the world and its experiences. It includes two types, experimental and logical. The former deals in transitivity and lexis and the latter is entangled in the process of connecting the meanings of clauses, Llinares \& Whittaker (2006). According to Llinares \& Whittaker (2006) the realization of relationships of interlocutors are interpersonal meta-function, whereas Halliday (1994), 
argued that the organization of language items in drafting a message require the cohesion and information in detail which are involved in textual meta-function. In addition, the overall concern of systemic linguists is to understand the enigma of how language learners use language in order to meet the criteria of social life. The major focus of the systemic linguists relies on the formation of meaning in the utterances or written text of the learners, or to analyze the change or influence of culture on the functions of language. Moreover, the relationship of context and language is also a major area of concern for these linguists. Context and language are unified terms. This is how linguists deduce the context from language.

Eggins (2004) argued that language is blind without context and if one is separated from the other, it becomes obscure with regards to meaning. Linguistically, text can be taken as anything which can be read or understood whether that thing be literary work, speech, conversation, signs on the street or a building etc. Moreover, a text usually consists of semantic units that combine to form a coherent set of messages giving out a meaning. Semantically a text constitutes a pattern of syntactic and semantic sentences forming a unified set of meanings joined together by the grammatical principles of language forming a meaningful or logical piece of writing. Halliday (1976) referred to 'text' as a meaningful unit of language comprising particular stylistic or textual constituents (semantic and syntactic properties of text) that provide cohesiveness inside the text and make the text function as a unified linguistic unit. Textual constituents regulate the straits and manners over which a meaning is conveyed, according to Halliday's practical semantic approach to language. In other words, it can be said that the textual constituents play a role in determining the type of text that is being encountered by the reader. A text can also be anything from which interpretation can be drawn (i.e. a magazine, a sign board, a novel, a conversation, a shirt, the arrangement of furniture in a room, etc.). Hence, text is anything which gives out a particular meaning, or through which any meaning can be drawn according to the context or circumstance of the text.

Furthermore, a text can be comprehended through textual analysis helping linguists to define and understand the features of any written or spoken text. Nunan (1993) proposed that a text is analyzed to determine its construction, subject matter and purpose of the meanings confined in the text (p.78). Choosing the kind of text to be considered, obtaining suitable text and defining a specific method to be practiced in examining the text are significant concerns in the textual analysis of text. Whenever a text is analyzed, a logical assumption about the utmost possible interpretation of the textual, semantic, and syntactic elements which can be made through text, are examined by linguists. Analysis of the use of actual language is the ultimate goal of discourse comprehension of any writing; Michael Halliday (1994) defined writing as any reliable stretch of textual or spoken language which can be analyzed linguistically. Halliday (1994) further suggested that initially the study of linguistics at sentence level included morphology and then examining the meaning of words leading to connotation of language use. However, he also agreed with an opposite approach that language can be comprehended if it is taken as an organization of meanings which are connected through deferent links for their expression. A language is interpreted as a system of meaning accompanied by forms through which the meanings can be expressed. His work mainly centers on 
understanding the system for how the text is structured rather than just grammar or meaning of the language. This leads to a term, which styles any text as meaningful, to be known as texture. Without texture in a text there will be isolated sentence grouped having no connection or relation to one another. Hence, unity and semantic relatedness can be achieved only by the texture of the text.

Moreover, there are variety of textual components through which text can be analyzed. Dolnik and Bajzikova (1998) suggested that cohesive elements, coherent elements, contemporary associations, illocutionary construction and expressive purposes of text are related to the product approach of the text and focus on a text-as-a-product view of the text; whereas text production, reception and interpretation are related to the process approach of the text, hence focusing on the text-as-a-process viewpoint of the text. News articles can be written and comprehended as moderately independent pieces of communication giving out a meaning, keeping in concern all the textual elements used in creating a skillful text. De Beaugrande and Dressler (1981) argued that text contains seven standards of textuality if taken as a conversational occurrence and those seven constitutive codes of textual conversation or communication include: cohesion, intentionality, coherence, intertextuality, acceptability, situationality, normativity and three regulative aspects of textual communication; appropriateness, efficiency, and effectiveness (p.98).

Likewise, cohesion plays substantial role in creating an interest and consistency in any verbal or written text and helps in the analysis of text. Halliday and Hasan (1997) proposed that cohesion stands for text-forming associations which are non-structural; suggesting that the idea of cohesion is concerned with meaning forming links in the text rather than grammar, therefore when the meanings form, semantic links occur in the text creating ties which result in simplified comprehension (pg. 7). A tie in a text is formed when a previously mentioned item is referred to again but depends on a different element. Sentences or utterances lack any type of relationship with each other if there are no semantic ties. The word semantic tie infers a relationship between two elements in the text suggesting that the semantic tie cannot be formed unless there is presence of at least two elements which share a specific semantic relation to each other. Halliday and Hasan (1997) argued these inner textual relations with two terms as "presupposing" and "the presupposed" which suggests that cohesion in a text makes one thing dependent on another leading to interdependency.

Furthermore, Nunan (1993) suggested that semantic ties are text creating elements which help authors to form links between the borders of utterances or sentences; aiding in tying them together in the text. Similarly, Eggins (1994) proposed cohesive devices as items, which relate to the means through which sections of the discourse may be joined together.

This research article explores the affiliation of error analysis with foreign language learning and describes a range of strategies that are used by learners in the process of learning a language. Moreover, it also explores the impact of error analysis during the language learning process and describes the difficulties faced by learners while learning a language. The variety in categories of error analysis gives teachers knowledge about 
the language learners' weaknesses. Focusing on the weak areas of foreigners learning a language, Corder (1981) described error analysis to be the systematic study of errors in a learners' language and is necessary for the improvement of techniques of language teaching. Errors are always expected and grammatical errors are a complex area of concern when writing in English. Non-native learners face a lot problem especially in China such as lack of vocabulary, tense form and pronunciation because of lack of English speaking teachers and speaking practice environment. Parents also plays substantive role in teaching English as a second language in China. In this view, this study fills the existing gap and highlight the role of native teachers in teaching as a second language in China.

\section{Research Design}

\section{Teaching methodology and curriculum}

Teaching methodology

The subjects spent two hours each week learning English with a native English-speaking teacher in classes ranging from five to six students and total twenty-one students. Various teaching methods such as direct method, role play activities, AV method were incorporated by the instructor throughout the class. In general, classes began with an introduction of the weekly topic in which prior knowledge of the subject was elicited from the students by the teacher. The key focus of the study was vocabulary, and grammar in writing, and speaking skills. Next, eight target-vocabulary words were taught primarily utilizing the present, practice, production method (PPP). Following the learning of target-vocabulary, a reading assignment was tasked and students read a story or informational text aloud which incorporated the target-words and displayed them in a native context. During and after the reading task, comprehension check questions (CCQs) were asked. Approximately $60 \%-70 \%$ of the class time was spent on elicitation of prior knowledge, vocabulary, reading tasks, and comprehension questions. The remaining portion of the class was focused on grammar and writing production, including parts of speech, punctuation, and writing cohesiveness. The major focus was paid to writing, vocabulary and grammar of the learners.

The native speaker is a graduate from Georgia University, USA. He belongs to the state of Georgia, the United States of America. He has been teaching English in China for the last five years. He is selected for this study because has many regular ESL courses to teach English language in Shanghai, China. Parents were also interviewed to know the interaction of learners with their parents in foreign language and to know the total time spend by learners in practicing a foreign language outside the classroom.

\section{Curriculum}

The curriculum taught to the students in the study was McGraw-Hill Education's Wonders Grade 2. It is comprehensive K-6 program built on the California Framework and the CA Common Core State Standards (www.mheducation.com, 2018). The textbook which is used as material in teaching English is known as 'Wonders' which is also widely popular in China. In March 2018, DaDaABC, a large Chinese education 
company, announced its partnership with McGraw-Hill Education stating that the Chinese company will incorporate book 'Wonders' into their own classes (www.prnewswire.com, 2018). Therefore, this book is used as a teaching material in this study.

\section{METHOD}

Participants

In total, twenty-one subjects partook in this study. Subjects were all native Mandarinspeakers from various cities and provinces of China. One of the subjects was excluded from the study because they failed to fully provide the needed data. Of the remaining twenty subjects, the mean age was 9.4 years old, with thirteen females and eight males. Of the twenty-one participants, nineteen were 4th grade students and two were 3rd grade. Subjects all spent a minimum of two hours per week with the same native English-speaking instructor, apart from the English courses required by their primary school curriculum. Consent was taken from their parents to conduct the study, and all the parents of these learners participated in providing feedback and responses required for this study.

\section{Data Collection}

Data was collected over the course of sixteen weeks. At the beginning of the period, a pre-test was given to investigate subject's prior knowledge of the material. At the end of the period, a post-test was taken by the students which included the information taught during the entire sixteen weeks. The goal of the tests was to find out the effectiveness of the native speaking teachers in the EFL classroom.

\section{Pre-test}

\section{Material}

The pre-test was administered using the medium of pencil and paper. The test was divided into four sections. Section one included a short story followed by five comprehension questions. Section two contained ten sentences whose word order were scrambled. The following section was a ten-question gap-fill task with the missing words being target-vocabulary. A word bank was provided from which subjects could choose. The fourth and final section was a writing assignment. Two topics were provided from which participants could choose and write about. Each section was worth ten points. Section one contained five questions with each worth two points. Meanwhile, both sections two and three contained ten questions, with questions being valued at one point each. In the final section, points were given subjected to the instructor's evaluation of student's ability to form both coherent and cohesive sentences and paragraphs. Examples from each section of the test can be seen in the appendix section of this paper.

\section{Procedure}

First, subjects were given clear instructions and examples by the teacher demonstrating how each section of the test was to be completed. Ninety minutes were allotted to take 
the test. Subjects were situated at various tables with adequate space in between in order to prevent the copying of answers and ensure students tests reflected their overall knowledge of the material. At the end of the session, tests were taken up by the instructor and the period was concluded.

\section{Post-test}

\section{Material}

The format of the post-test was the same as the pre-test, including the same amount and type of sections, questions, and question point values. Pre-test and post-test were designed to determine the vocabulary, writing ability of Chinese students who were the actual participants of this study. The content of the questions was altered; however, the target knowledge remained the same as in the pre-test. Similarly, procedure for post-test was also same as that of pre-test.

Learners' study-habits questionnaire

A questionnaire was distributed to the parents of the learners in order to investigate the student's English study habits. The objective in learning about the parent's biographical information and the learners' study habits was investigated their relationship with students pre- and post-test scores.

\section{Material}

The questionnaire included two sections. The first section inquired about the parent's biographical information including: Name, relationship to student, mother tongue, profession, education level, medium language of highest level of education achieved, hometown, gender, and other languages known. Section two sought to discover the students weekly study habits in regards to English. Questions concerned students time spent studying, mediums of study, and frequency of student-parent English interactions. Questions were answered based on a liker-scale rating. Possible answers ranged from strongly disagree, disagree, neither agree nor disagree, agree, and strongly agree.

\section{Procedure}

The questionnaire was distributed to the parents through a major Chinese social media platform. Questionnaires were given in written Mandarin-Chinese translated from English by a fluent Mandarin-speaker. A brief opening paragraph gave detailed instructions about the filling out of the form as well as the intended use of the information for research purposes.

\section{FINDINGS}

Figure 1 and 2 show the frequency distribution of pre-test and post-test scores. The yaxis (frequency) shows how many subjects achieved a given score. Meanwhile, the $\mathrm{x}$ axis (scores) shows the interval of scores. 


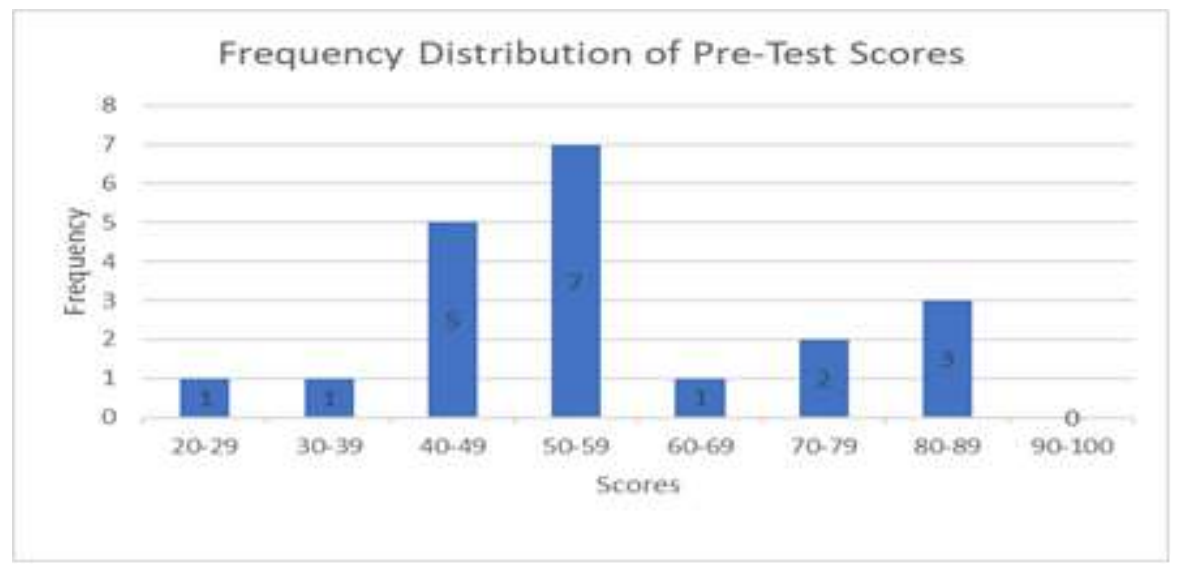

Figure 1

Frequency Distribution of Pre-Tests

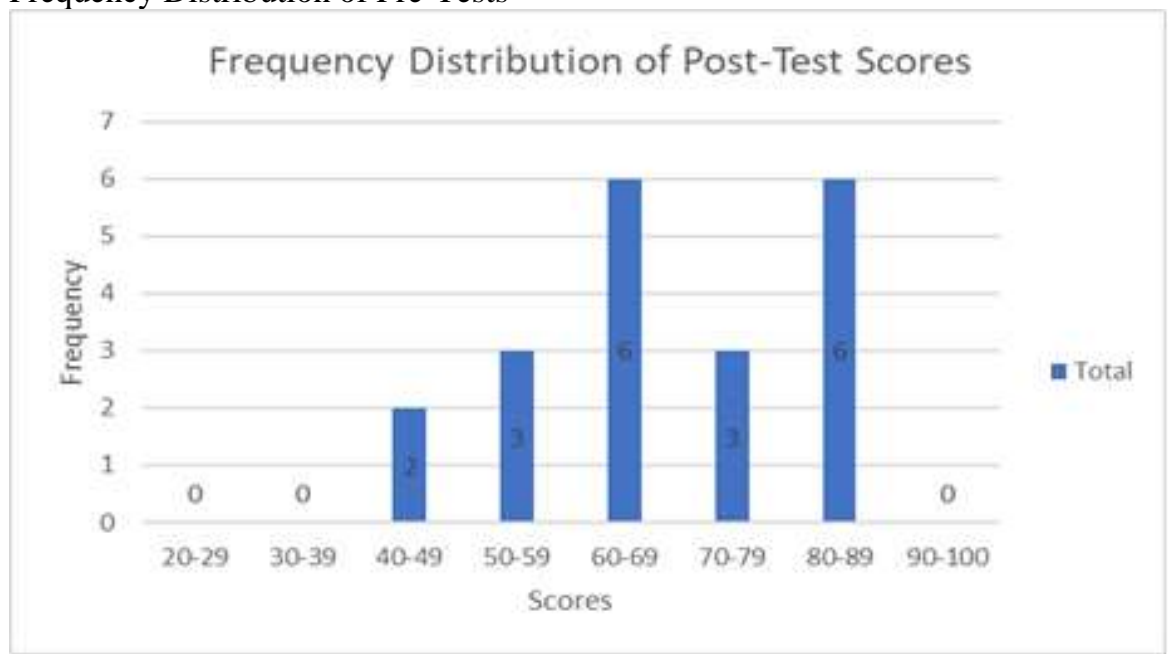

Figure 2

Frequency Distribution of Post-Test Scores

According to Figure 1, 14 of the 20 subjects (70\%) of the subjects had a score of less than 60 points and 6 about it $(30 \%)$. Figure 2, meanwhile, details the frequency distribution of the post-test scores among the same group of students. The results of the post-test show that after a 16-week period of learning 15 out of 20 students registered a score of more than 60 points $(75 \%)$ and only 5 receiving a score of less than 60 points $(25 \%)$. From this data we can gather that there was an overall increase in the scores of the subject among the entire group. Finally, Figure 3 shows a comparison of bother preand post-test scores among all of the subjects. The chart below provides a clear picture of the increase in test scores after the teaching period. 


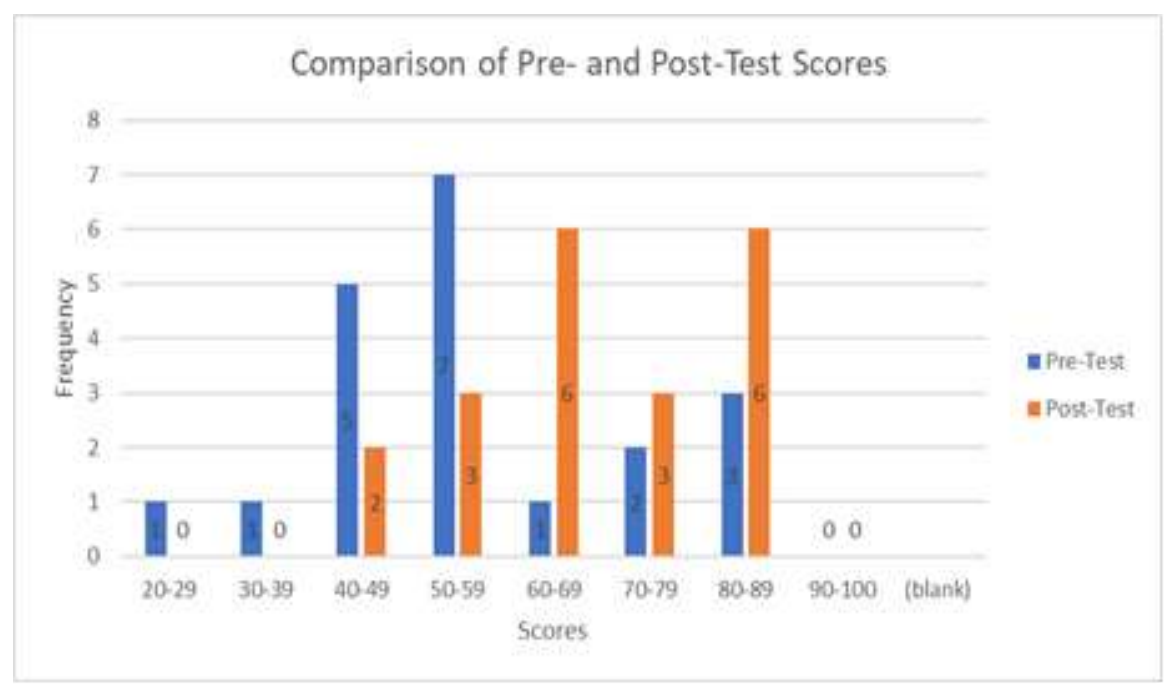

Figure 3

Comparison of Pre and Post Test

Figure 4 and 5 found below display the results of the questionnaire given to the parents of the subjects in the study. Questions 1-13 were answered based on a five-point likerscale ranging from strongly disagree to strongly agree. If strongly disagree was selected it was assigned a value of 1 , disagree was assigned a value of 2 , neither agree nor disagree was given 3 points, agree was given 4 , and finally strongly agree was given a value of 5 points. Questions 1, 2, 3, 4, 5, 9, 10, 11, 12, and 13 focused on subject's time spent being engaged in English, whether through direct teacher instruction or outside of the classroom activities such as watching English TV shows. Questions 5, 6, and 7 were related to parent's involvement in their child's English study habits. The points were summed and the total value was used to determine the subject's English study habits and the parent's direct involvement in the learning process. Higher scores denote more time spent studying and/or higher parental involvement, while lower scores denote less. Table 4 shows learners study habits and time spent involved in English study. 


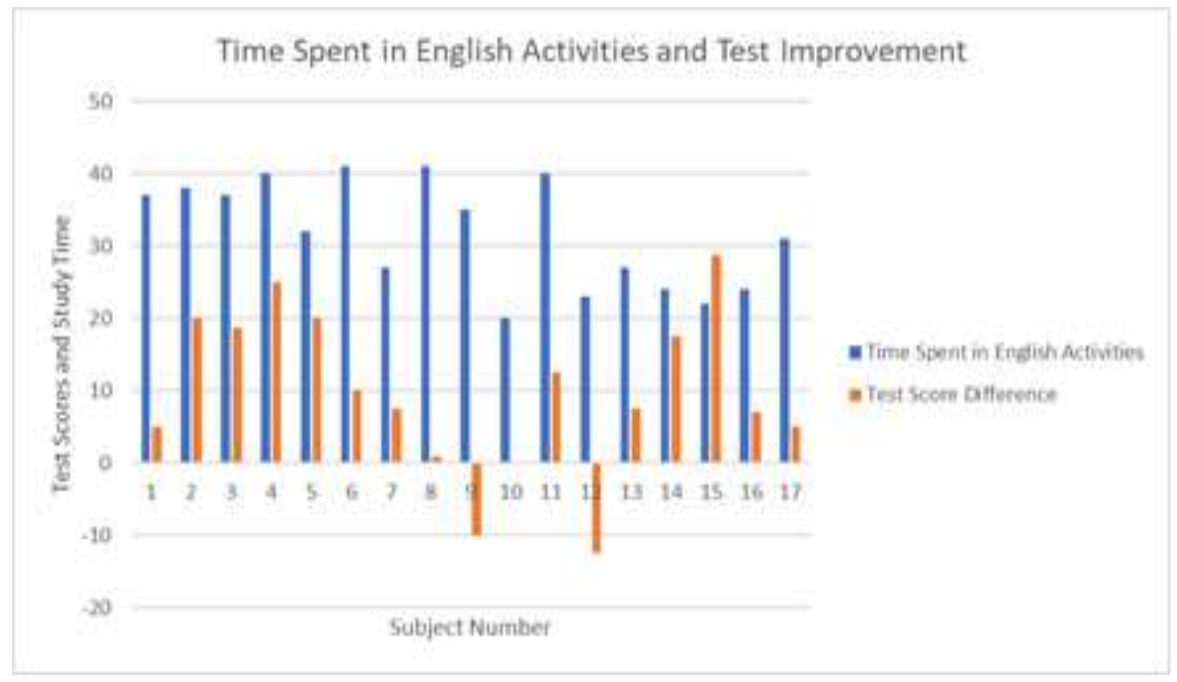

Figure 4

Time Spent in English Activities and Test Improvement

From Figure 4 it is difficult to tell whether or not an increase in time spent in English outside of mandatory courses at school played an important role in increasing the subject's English language abilities. It can be seen that while some subject spent less amounts of time outside the classroom, the learner still showed significant improvement. Meanwhile, some subjects' spent more time involved in English activities, but very little progress was made.

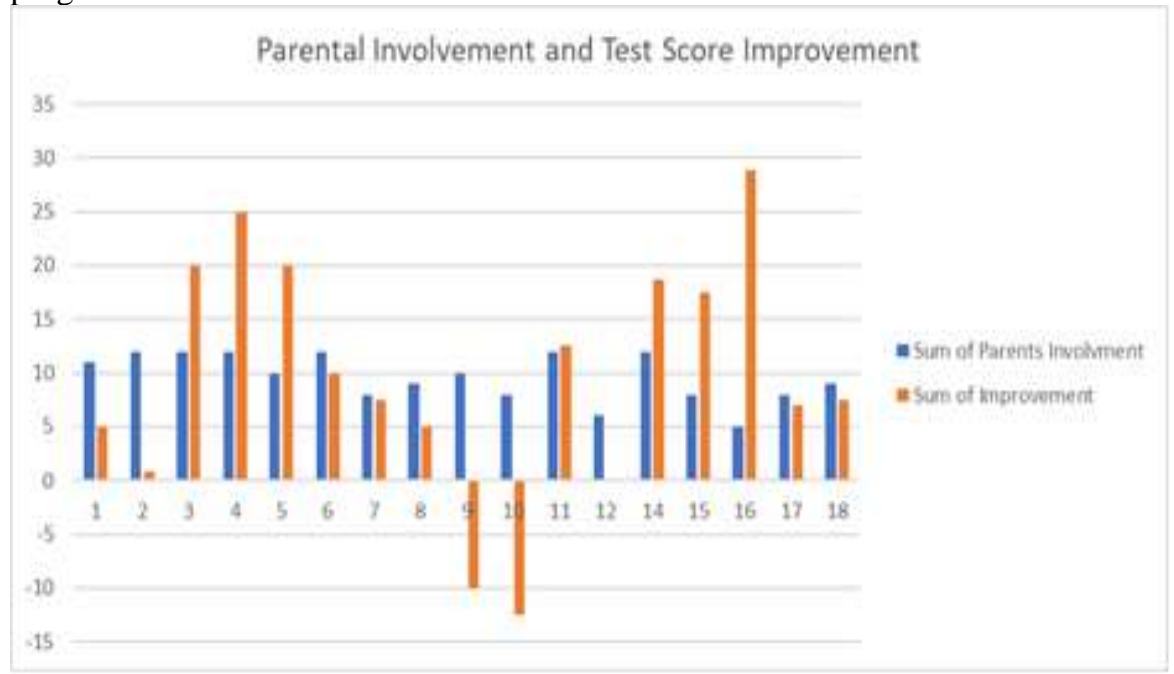

Figure 5

Parental Involvement and Test Score Improvement 
In figure 5, the results of a questionnaire given to at least one of the learners' parents are displayed. Of the twenty participants in the study, two different participants' parents did not complete the survey, meaning questionnaires of only eighteen participants are shown here. Under each participant (designated by numbers 1-18), the column on the left shows how involved each of the eighteen learner's parents are in the English studies, meanwhile, the column on the right shows how many points the learners either increased or decreased in their pre- / post-test performance score. The score for parental involvement in the left column was given based on the answers given in the questionnaire. For example, the questionnaire employing a Likert-scale, means that an answer of 'strongly agree' is awarded 3 points, whereas an answer of 'agree' is only awarded 2 points. As seen in figure 5, parental involvement in the learners' performance leads to varying degrees of improvement on the post-test performance.

\section{DISCUSSION}

The first research question presented in this study asked about the impact of native English-speakers in the EFL classroom. Based on the findings in this study a native teacher can have a significant effect on the positive development of English language learners. Secondly, it was asked what the correlation between study habits and L2 development was. The results from the present study are somewhat mixed. Possible reasons for this could lie in the fact that certain students, although spending time studying English outside of the classroom, misinterpreted or misunderstood various elements, whether grammar, vocabulary, or others. The three exceptions being participants 9 and 10, both of whom decreased, and participant 12, who showed no fluctuation in performance between pre- and post-test performance. Although most participants whose parents are involved in the learners' studies improved their performance in the post-test could indicate that parental involvement does have some effect on the learner's performance, the inconsistent patterns of improvement in post-test performance in relation with the amount of parental involvement may mean that there are other factors contributing to the learner's performance. Those factors were not investigated in this study, but could be the basis for further research in future studies. As a result of the findings of the questionnaire, it may be inferred that while parental involvement plays a role in the performance of leaners' development in the areas reading comprehension, vocabulary, and writing ability, the degree of impact the role of involvement plays is unclear in the present study.

Lastly, this study asked about the parent's role in second language practice. Again, the outcome of this study showed mixed results. While direct involvement from a parent with an advanced level of English would certainly be helpful, it is also probable that those with lesser English abilities might have had a negative effect on the students overall learning of the material.

\section{CONCLUSION}

The presence of a native English-speaker in the EFL classroom as well as involvement from parents in a learner's L2 study can no doubt benefit the learning process. An adequately equipped native teacher can provide advantages such as producing native 
grammatical structures, vocabulary, and pronunciation. The study answers the very question on impact of native teachers in teaching ESL in non-native countries. The results of the study showed positive impact and this impact cannot be acieved by nonnative teachers in teaching English as a second language. This phenomenon can also be observed through the parents of non-native learners in China that non-native teachers usually are found lacking in accurate pronunciation of words, fluency of speech, and vocabulary. However, the case is non-native also participate well in teaching English as a second language because of their experience and academic training in teaching process.

On the other hand, parental involvement in their child's study of an L2 could have a positive or negative effect, possibly based on their own understanding of English and the way in which they transmit it to the child. While good study habits should be encouraged by parents, it is also possible that a parent's misusage of English could be transmitted to their learner. Learning an L2 outside of its natural environment, such as in the classroom or through direct study, is a common practice in everyday life in most countries. Therefore, careful attention should be paid not only to the learner's development, but also the input given by their teacher, whether native or not, and their parents. With the proper methods, habits, and environment; learners can have a maximized experience in the L2 learning process.

\section{REFERENCES}

Arends-Kuenning, M., \& Amin, S. (2000). The effects of schooling incentive programs on household resource allocation in Bangladesh.

Braine, G. (1999). From the periphery to the center: One teacher's journey. Non-native educators in English language teaching, 15, 28.

Canagarajah, S. (2002). Multilingual writers and the academic community: Towards a critical relationship. Journal of English for Academic Purposes, 1(1), 29-44.

Corder, S. P. (1967). The significance of learners 'errors ', IRAL. Vol V/4. Reprinted in SP Corder (1981). Error analysis and interlanguage (pp. 19-27).

Derwing, T. M., Rossiter, M. J., Munro, M. J., \& Thomson, R. I. (2004). Second language fluency: Judgments on different tasks. Language learning, 54(4), 655-679.

Dolnik, J. (1998). BAJZIKOVA: Textova lingvistika. J. Dolnik.-Bratislava: Stimul.

De Beaugrande, R. A., \& Dressler, W. U. (1981). Introduction to text linguistics (Vol. 1). London: Longman.

Eggins, S. (2004). Introduction to systemic functional linguistics. A\&C Black.

Falvey, P., \& Coniam, D. (2018). Concluding Comments on the Benchmarking (LPATE) Project: Strengths, Weaknesses and Constraints. In High-Stakes Testing (pp. 399-416). Springer, Singapore. 
Halliday, M. A. K. (1994). Spoken and written modes of meaning. Media texts: Authors and readers, 7, 51-73.

Halliday, M. A. K. (1976). Anti-languages. American Anthropologist, 78(3), 570-584.

Halliday, M. A. (1997). K \& Hasan, Ruqaiya. 1976. Cohesion in English.

Kim, J. (2009). From Mee-gook to Gook: the Cold War and racialized undocumented capital in Chang-rae Lee's Native Speaker. MELUS: Multi-Ethnic Literature of the US, 34(1), 117-137.

Llinares, A., \& Whittaker, R. (2006). Linguistic analysis of secondary school students' oral and written production in CLIL contexts: Studying social science in English. Current Research on CLIL, 28.

Medgyes, P. (1992). Native or non-native: who's worth more?. ELT journal, 46(4), 340349.

McGraw-Hill Education's Wonders Grade 2: Retrieved from: www.prnewswire.com

Mcgraw-hill Connect Retrieved from: https://connect.mheducation.com

Nunan, D. (1993). Task-based syllabus design: Selecting, grading and sequencing tasks. MULTILINGUAL MATTERS, 55-55.

Phillipson, R. (1992). ELT: the native speaker's burden?. ELT journal, 46(1), 12-18.

Reves, T., \& Medgyes, P. (1994). The non-native English speaking EFL/ESL teacher's self-image: An international survey. System, 22(3), 353-367.

Rampton, B. (1996). Language crossing, new ethnicities and school. English in Education, 30(2), 14-26.

Rothaermel, F. T. (2016). Strategic management: concepts (Vol. 2). McGraw-Hill Education. 